\title{
Evaluación de un sistema para la micorrización in vitro en plantas de mora de castilla (Rubus glaucus, Benth)
}

\author{
Urley Adrian Pérez-Moncada', María Margarita Ramírez-Gómez ${ }^{1}$, Víctor Manuel Núñez-Zarante², \\ Marcela Franco-Correa ${ }^{3}$, Gabriel Roveda-Hoyos ${ }^{4}$ \\ ${ }^{1}$ Centro de Biotecnología y Bioindustria (CBB), Laboratorio de Microbiología Molecular, ${ }^{2}$ Laboratorio de Genética Molecular Vegetal, Corporación \\ Colombiana de Investigación Agropecuaria (CORPOICA). Cundinamarca., Colombia. \\ ${ }^{3}$ Unidad de Investigaciones Agropecuarias (UNIDIA), Facultad de Ciencias, Pontificia Universidad Javeriana. Bogotá D.C., Colombia. \\ ${ }^{4}$ Facultad de Agronomía, Universidad Nacional. Bogotá D.C., Colombia. \\ *urleyadrian@gmail.com
}

Recibido: 15-03-2012; Aceptado: 03-07-2012

\begin{abstract}
Resumen
Objetivo. Obtener un sistema de micorrización in vitro en sistemas de cultivo autotrófico para plantas de mora de castilla (Rubus glaucus, Benth). Materiales y métodos. Se utilizaron esporas y fragmentos de raíces con vesículas del Hongo Formador de Micorriza Arbuscular (HFMA) Glomus sp. (GEV02). Se estableció un sistema de cultivo autotrófico para plántulas de mora, comparando dos métodos de inoculación directa con el HFMA. Se cuantificó el número de esporas producidas, la longitud del micelio extraradical; así como el porcentaje de colonización del HFMA. Adicionalmente se midió la longitud aérea y radical, el peso fresco y seco de la parte foliar y radical para determinar el desarrollo de las plantas. Resultados. El sistema de cultivo autotrófico fue exitoso para plantas de mora de castilla (Rubus glaucus, Benth); observándose un óptimo crecimiento de la parte aérea y radical de la planta. Adicionalmente en este estudio se pudo obtener un sistema que permitió el desarrollo de Glomus sp (GEV02) bajo condiciones in vitro, con formación de estructuras típicas de la simbiosis como una buena colonización intraradical, con producción de arbúsculos y vesículas, así como el desarrollo de micelio extraradical con hifas ramificadas y la formación de nuevas esporas. Conclusión. Las plantas de mora micropropagadas se asociaron con éxito, por primera vez, con un hongo formador de micorriza arbuscular bajo condiciones in vitro, permitiendo el desarrollo del sistema simbiótico HFMA Glomus sp., asociado a las raíces de plántulas de mora castilla micropropagadas.
\end{abstract}

Palabras clave: hongos formadores de micorriza arbuscular (HFMA), cultivo autotrófico, Rubus glaucus Benth, Glomus sp (GEV02), micorrización in vitro.

\begin{abstract}
Evaluation of an in vitro mycorrhization system of blackberry plants (Rubus glaucus, Benth). Objective. Obtain an in vitro mycorrhization system in autotrophic culture systems of blackberry plants (Rubus glaucus, Benth). Materials and methods. We used spores and root fragments with vesicles of Arbuscular Mycorrhizal Fungus (AMF) Glomus sp (GEV02). We established an autotrophic culture system of blackberry plantlets comparing two methods of direct inoculation of the AMF. We measured the number of spores produced, the length of the extraradical mycelium as well as the percentage of colonization of the AMF. Additionally, we measured the shoot and root length, and the fresh and dry weight of the leaf and root parts to determine the plant development. Results. The autotrophic culture system was successful for blackberry plants (Rubus glaucus, Benth; an optimal shoot and root growth was observed. Additionally, we obtained a system that allowed the development of Glomus sp. in in vitro conditions, with the formation of structures typical of the symbiosis as well as a good intraradical colonization, with the production of arbuscules and vesicles, development of extraradical mycelium with branched hyphae, and formation of new spores. Conclusion. For the first time, micropropagated blackberry plants associated successfully with an AMF under in vitro conditions, enabling the development of the symbiotic system AMF Glomus sp. associated to roots of micropropagated blackberry plantlets.
\end{abstract}

Key words: arbuscular mycorrhizal fungi (AMF), autotrophic culture, Rubus glaucus Benth, Glomus sp. (GEV02), in vitro mycorrhization. 


\section{Resumo}

A valiação de um sistema para micorrização in vitro em plantas de amora-preta (Rubus glaucus, Benth). Objetivo. Obter um sistema de micorrização in vitro em sistemas de cultura autotróficos para plantas de amora-preta (Rubus glaucus, B enth). M ateriais e métodos. Foram usados esporos e fragmentos de raízes com vesículas do Fungo Formador M icorrízico A rbuscular (FFM A) G lomus sp. (GEV 02). Foi estabel ecido um sistema de cultivo autotrófico para mudas de amora-preta, comparando dois métodos de inoculação direta com o FFM A . Foi quantificado o número de esporos produzidos, o comprimento do micélio extra radicular; bem como a porcentagem de colonização do FFM A. A lém disso, foi medido o comprimento e o peso fresco e seco da parte fol har e radicular para determinar 0 desenvolvimento das plantas. Resultados. 0 sistema de cultivo autotrófico foi bem-sucedido para as plantas de amora-preta (Rubus glaucus, B enth), onde foi observado um crescimento ótimo da parte aérea e da raidicular da planta. A lém disso, neste estudo foi obtido um sistema que permitiu o desenvolvimento de G lomus sp (GEV 02) sob condições in vitro, com formação de estruturas típicas da simbiose como uma boa colonização intra radicular, com produção de arbúsculos e vesículas, assim como o desenvolvimento de micélio extra radicular com hifas ramificada e a formação de novos esporos. Conclusão. As plantas de amora-preta micropropagadas associaram-se com sucesso, pela primeira vez, com um fungo formador micorrízico arbuscular em condições in vitro, permitindo o desenvolvimento do sistema simbiótico FFM A G lomus sp., associado às raízes das plântulas de amora-preta micropropagadas.

Palavras-chave: fungos formadores micorrízicos arbusculares (FFM A), o cultivo autotrófico, Rubus glaucus B enth, G lomus sp (GEV 02), micorrização in vitro.

\section{Introducción}

La mora de castilla (Rubus glaucus, Benth), pertenece a la familia Rosácea, es una especie originaria de los Andes Tropicales de A mérica. Esta especie se distribuye ampliamente en el país, se encuentra en forma silvestre, desde el departamento del Putumayo hasta el $\mathrm{V}$ alle del $\mathrm{M}$ agdalena y es posible cultivarla en altitudes entre 2.000 y 3.200 metros (1). De acuerdo con el Ministerio de A gricultura y Desarrollo Rural, la producción de mora en Colombia creció de 59.406 toneladas/año en 1999 a 82.135 toneladas/año en 2010; en este mismo período de tiempo, aumentó el área sembrada de mora de 7.062 hectáreas a 11.883 hectáreas. Siendo los departamentos de Cundinamarca, Santander y A ntioquia, los mejor posicionados en aérea y producción (2). A pesar de la riqueza y del gran potencial de la mora, esta especie no ha adquirido el grado de importancia esperado, lo cual puede atribuirse a varias limitaciones dentro de las que se destaca, la propagación asexual mediante acodos 0 estacas que frecuentemente, transmiten enfermedades fúngicas, bacterianas y virales que dejan grandes pérdidas al agricultor (3), por cuanto se hace necesario el desarrollo de técnicas al ternativas de propagación, mediante el cultivo de tejidos para garantizar una semilla vegetativa de alta calidad fisiológica, fitosanitaria y genética. El cultivo de tejido vegetal in vitro o micropropagación, constituye dentro de la biotecnología moderna, la técnica que mayor aporte práctico ha brindado en el sector (4). A pesar de los múltiples beneficios que genera la micropropagación, existen limitantes para un uso más extendido de esta técnica tales como transferencia de plántulas en condiciones in vitro a condiciones ex vitro, que constituye uno de los pasos más críticos de la micropropagación debido al alto grado de mortal idad de plántulas (entre 50 y $90 \%$ ). Estas pérdidas se producen por problemas de aclimatación, como consecuencia de una cutícula poco desarrollada, estomas no funcionales con un inadecuado control del estado hídrico de la planta y un sistema radical débil, que facilita la deshidratación (5-8). Las nuevas propuestas biotecnológicas sugieren aprovechar el recurso de la micropropagación, acompañada de la inoculación con Hongos Formadores de Micorriza A rbuscular (HFM A). La estrategia de la inoculación con HFM A se ha implementado con éxi to para reducir el estrés durante el trasplante y garantizar un crecimiento rápido tanto del material vegetal propagado en condiciones de vivero 0 invernadero, como en plantas originadas en cultivo in vitro, debido a los efectos benéficos de esta asociación sobre la nutrición y el crecimiento de las plantas (8, 9-12).

V oets et al., (2005) desarrollaron un sistema de micorrización in vitro que podría ser adaptado a mora de castilla (13). Este sistema, permitió la asociación exitosa de HFMA a plántulas de papa micropropagadas; las raíces y los HFM A se desarrollaron bajo estrictas condiciones de cultivo in vitro, mientras que la parte aérea se desarrollaba al aire libre, con una intensidad lumínica al ta que permitía la fotosíntesis de la planta, las hifas que emergían de las esporas eran capaces de colonizar las raíces, de desarrollar micelio extraradical y producir nuevas esporas.

En el presente estudio se adaptó y evaluó un sistema de cultivo autotrófico para la micorrización in vitro de plántulas micropropagadas de mora de castilla (Rubus glaucus, B enth), este tipo de sistema (13), permite observar en forma directa, no destructiva, la dinámica de la simbiosis incluyendo producción de esporas, la colonización intraradical de las raíces y su capacidad de reproducir el ciclo de vida del hongo, mientras la planta se desarrolla al aire libre con una intensidad lumínica que permite la fotosíntesis de esta. 


\section{M ateriales y métodos}

\section{Producción de plántulas de mora in vitro}

Las plántulas de mora de castilla (Rubus glaucus, Benth) variedad sin espinas fueron proporcionadas por el $L$ aboratorio de M icropropagación de Plantas del Centro de B iotecnología y Bioindustria - CBB de CORPOICA, provenientes de una etapa de multiplicación. EI material vegetal se enraizó en el medio basal Lepoivre modificado (14), el cual se preparó a partir de soluciones madre de macronutrientes, micronutrientes, vitaminas y FeNaEDTA, suplementado con $0,4 \mathrm{mg}$ de tiamina, $100 \mathrm{mg}$ de inositol, $0.1 \mathrm{mg}$ de Á cido Indol B utírico y $20 \mathrm{~g}$ de sacarosa. Después de ajustar el pH a 5,8; se añadieron $7 \mathrm{~g}$ de agar. A continuación se repartieron $30 \mathrm{ml}$ de medio en tubos y se introdujeron en autoclave $\left(120^{\circ} \mathrm{C}\right.$ durante $\left.20 \mathrm{~min}\right)$. L as plántulas se mantuvieron en un cuarto de crecimiento con una temperatura promedio de $22^{\circ} \mathrm{C}$, fotoperíodo de 16 horas luz / 8 horas oscuridad y una intensidad lumínica de 200 lux.

\section{Obtención del inóculo de HFM A}

Se utilizaron esporas de G lomus sp. (GEV 02), provenientes de un cultivo de mora de castilla (Rubus glaucus, B enth). La multiplicación del HFM A se realizó bajo condiciones de invernadero utilizando como hospedero cebolla de bul bo (Allium cepa L ). La producción de plantas de cebolla se hizo a partir de semillas sexuales del híbrido Y ellow Granex F1PRR; las semillas fueron desinfectadas con hipoclorito de sodio al $2 \%$ y sembradas en turba $C$ anadiense Growing M ix F15. A las 16 semanas de crecimiento, se procedió a extraer el inoculante, consistente en una mezcla de sustrato, esporas y raíces micorrizados. $L$ as esporas utilizadas se aislaron del inoculante a través de la técnica de tamizado húmedo y decantación (15). A dicional mente, se seleccionaron bajo un estéreo microscopio (Olympus SZ60) y se cortaron fragmentos de raíces de $1 \mathrm{~cm}$ de longitud, que contenían gran cantidad de vesículas. Estos dos tipos de propágulos infectivos (esporas y fragmentos de raíces con vesículas) fueron desinfectados (16) y colocados en placas de Petri que contenían medio M odificado Strullu - Romand (M SR) (17) y se incubaron en oscuridad durante 2 semanas a 25 C en posición invertida, hasta su posterior germinación.

\section{Sistema de cultivo autotrófico para la micorrización in vitro de plántulas de mora}

Se establ eció un sistema de culti vo autotrófico para plántulas de mora (13), comparándose dos métodos de inoculación directa con el HFM A Glomus sp. (GEV 02). En el primero, se utilizaron fragmentos de raíces con vesículas y en el segundo se utilizaron esporas individuales. Se realizaron dos orificios en un extremo de una placa de Petri $( \pm 2 \mathrm{~mm}$ de diámetro), uno en la base y otro en la tapa, las placas contenían $30 \mathrm{ml}$ de medio M SR sin sacarosa ni vitaminas y solidificado con $3 \mathrm{~g} / \mathrm{L}$ de Phytagel (17). A continuación se transfirieron plántulas de mora de castilla micropropagadas de 8 semanas de edad (de $3 \mathrm{~cm}$ de longitud aproximadamente) que estaban creciendo en sistemas de cultivo in vitro. Las raíces se colocaron en contacto con la superficie del medio, mientras que el tallo sobresalía a través del orifico de la placa. Se tomaron 5 esporas y 5 fragmentos de raíces con vesículas previamente desinfectados y germinados de $G$ lomus sp. (GEV 02) y fueron colocados en las proximidades de las raíces de las plántulas de mora en cada placa de Petri, estas se sellaron con papel parafilm y el orificio se cubrió con grasa de silicona (E M erck, D-6100 Darmstadf, F R. Germany) para evitar contaminaciones. Los sistemas autotróficos se ubicaron verticalmente en una cámara húmeda y toda la estructura se mantuvo en un cuarto de crecimiento con una intensidad lumínica de $16 \mathrm{~h}$ luz / $8 \mathrm{~h}$ oscuridad y una temperatura de $22{ }^{\circ} \mathrm{C}$ día/ $18{ }^{\circ} \mathrm{C}$ noche. Periódicamente, dependiendo de la necesidad de las plantas, se añadió medio M SR sin sacarosa ni vitaminas, esterilizado a $120^{\circ} \mathrm{C}$ durante 20 minutos, a las placas de Petri para mantener un nivel adecuado de nutrientes a las plantas.

\section{Diseño experimental}

Se realizó un diseño completo al azar, con tres tratamientos y 5 repeticiones. Cada sistema de cultivo in vitro autotrófico fue considerado como una unidad experimental. L os tratamientos eval uados fueron: un tratamiento sin inocular (control), un tratamiento inoculado con fragmentos de raíces con vesículas y un tratamiento inoculado con esporas individuales. A partir de la cuarta semana, se realizaron observaciones de contacto entre las hifas fúngicas y las raíces de las plántulas de mora utilizando un estéreo microscopio (Olympus SZ60). A partir de la quinta y hasta la novena semana se eval uaron variables a nivel simbiótico y fisiológico. Para las variables a nivel simbiótico se cuantificó el número de esporas producidas con el fin de determinar el desarrollo fúngico y en la novena semana, se midió la longitud del micelio extraradical con el método de intersección en placa (18); así como el porcentaje de colonización de HFM A, empleando la metodología de tinción con azul de tripán (19). A dicionalmente, se tomaron las medidas de la col onización radical, donde se cuantifica la frecuencia de micorrización $(\% \mathrm{~F})$, que considera el número de raíces colonizadas con relación al total de raíces por planta e intensidad de micorrización (\%l), que indica el porcentaje de colonización por raíz; asignando a cada fragmento un número de 0 a 5 en función del nivel de infección por el hongo, así como un valor A 0 hasta A 3 con base en la riqueza de arbúsculos del fragmento estudiado 
(20). Posteriormente empleando un programa informático se calculó la frecuencia de colonización, la intensidad de la misma y la riqueza de arbúsculos (21). A nivel fisiológico, se evaluó la longitud de las raíces y de la parte aérea. A la novena semana se midió el peso fresco y seco de la parte foliar y radical, para determinar el desarrollo de las plantas.

\section{Análisis estadístico}

EI análisis de los datos se realizó utilizando el paquete estadístico SA S System. Se realizó un análisis de varianza (A N OV A) para los datos registrados con una distribución normal y homogeneidad de varianzas. Posteriormente, los datos fueron sometidos a una prueba de medias con Tukey para observar diferencias significativas $(P \leq 0,05)$ entre tratamientos.

\section{Resultados}

\section{Sistema de cultivo autotrófico para la micorrización in vitro de plántulas de mora}

En este estudio se pudo obtener un sistema que permitió el desarrollo del HFMA Glomus sp. (GEV02) bajo condiciones in vitro, con formación de estructuras típicas de la simbiosis como una buena colonización intraradical, observándose los primeros puntos de contacto entre las hifas del hongo y las raíces de las plantas a la cuarta semana después de la inoculación, con producción de arbúsculos y vesículas, así como el desarrollo de micelio extraradical con hifas ramificadas, BAS (del inglés B ranched Absorbing Structures, Estructuras Ramificadas de A bsorción), cuya hipotética función es la absorción de nutrientes del suelo (22). Esta hi pótesis está respaldada por las modificaciones estructurales que ocurren a nivel del BA S; una disminución progresiva de la pared hacia el ápice de las hifas, lo que facilitaría la absorción de nutrientes y un aumento en el número de mitocondrias en la base del mismo, que aumenta la disponibilidad de energía para el transporte (23) y finalmente la formación de nuevas esporas (Figura 1); tal y como se describen en el desarrollo de cultivos monoxénicos de HFMA utilizando fragmentos de raíces de zanahorias transformadas empleando Agrobacterium rhizogenes $(24,25)$; sin la necesidad de realizar muestreos destructivos. Estos resul tados concuerdan con los obtenidos por varios autores en plantas autótrofas bajo condiciones de cultivo in vitro $(13,26-29)$, donde ocurrió asociación exitosa de Glomus intraradices (M UCL 41833, 43194) y G lomus sp. (M UCL 43195) con las plantas micropropagadas. A dicional mente, el sistema autotrófico fue exitoso para plántulas de mora de castilla (Rubus glaucus, Benth) variedad sin espinas; observándose un óptimo crecimiento de la parte aérea y radical de las plantas (Figura 2). Las plantas se asociaron con G lomus sp. (GEV 02) en medio M SR, utilizado para el cultivo de órganos de raíces de zanahoria transformadas (30). El medio carecía de sacarosa y vitaminas, el cual fue utilizado en trabajos realizados para la micorrización in vitro de papa (13), vid (27), M edicago truncatula (26, 29) y banano (28).

\section{Resultados experimentales}

A nivel simbiótico según el análisis de varianza (GLM), no se observaron diferencias estadísticas significativas $(P \leq 0,05)$ en los dos tratamientos inoculados con $G$ lomus sp. (GEV 02) en cuanto a los indicadores de asociación simbiótica como la frecuencia de micorrización $(\% F)$, intensidad de la micorrización (\%l), intensidad de arbúsculos (\%a), micelio extraradical y formación de nuevas esporas (Tabla 1). Las raíces de las plantas de mora fueron colonizadas por Glomus sp. (GEV 02) observándose un $100 \%$ en la frecuencia de micorrización (\%F). Las micorrizas arbusculares observadas fueron de tipo Arum, en que las hifas crecen en los espacios intercelulares del córtex de la raíz, y los arbúsculos se desarrollan como ramificaciones terminales intracelulares (30) (Figura 3). La colonización fue observada principalmente en las raíces primarias y secundarias.

A nivel fisiológico, las plantas inoculadas con fragmentos de raíces con vesículas o con esporas individual es de G Iomus sp. (EV 02) tuvieron una mayor producción de biomasa aérea y radical, observándose diferencias significativas en estos tratamientos con respecto al control de acuerdo con la prueba de Tukey (Figura 4), y en el momento de la cosecha (novena semana) las raíces ocupaban casi todo el volumen de la placa de Petri. Estos incrementos en biomasa bajo el sistema autotrófico puede asociarse a efectos nutricional es favorables vinculados con la asociación simbiótica in vivo, aunque también puede verse reflejado un efecto hormonal y/o fisiológicos de las especies de HFM A sobre las plantas que colonizan (31). Para las variables longitud aérea y radical, no se observaron diferencias estadísticas significativas entre los tratamientos inoculados con respecto al control, de acuerdo con el análisis de varianza (GLM). Sin embargo, los valores obtenidos en promedio de la longitud aérea y radical en los tratamientos inoculados con esporas $(6,7$ y $171,5 \mathrm{~cm})$ y fragmentos de raíces con vesículas $(6,5$ y $204,5 \mathrm{~cm})$ de Glomus sp. (GEV 02) fueron más al tos que el control $(5,7$ y $149,8 \mathrm{~cm})$ a la novena semana de ser evaluados, y estos tratamientos inoculados se pudieron cosechar una semana antes que el control (Figura 5). 


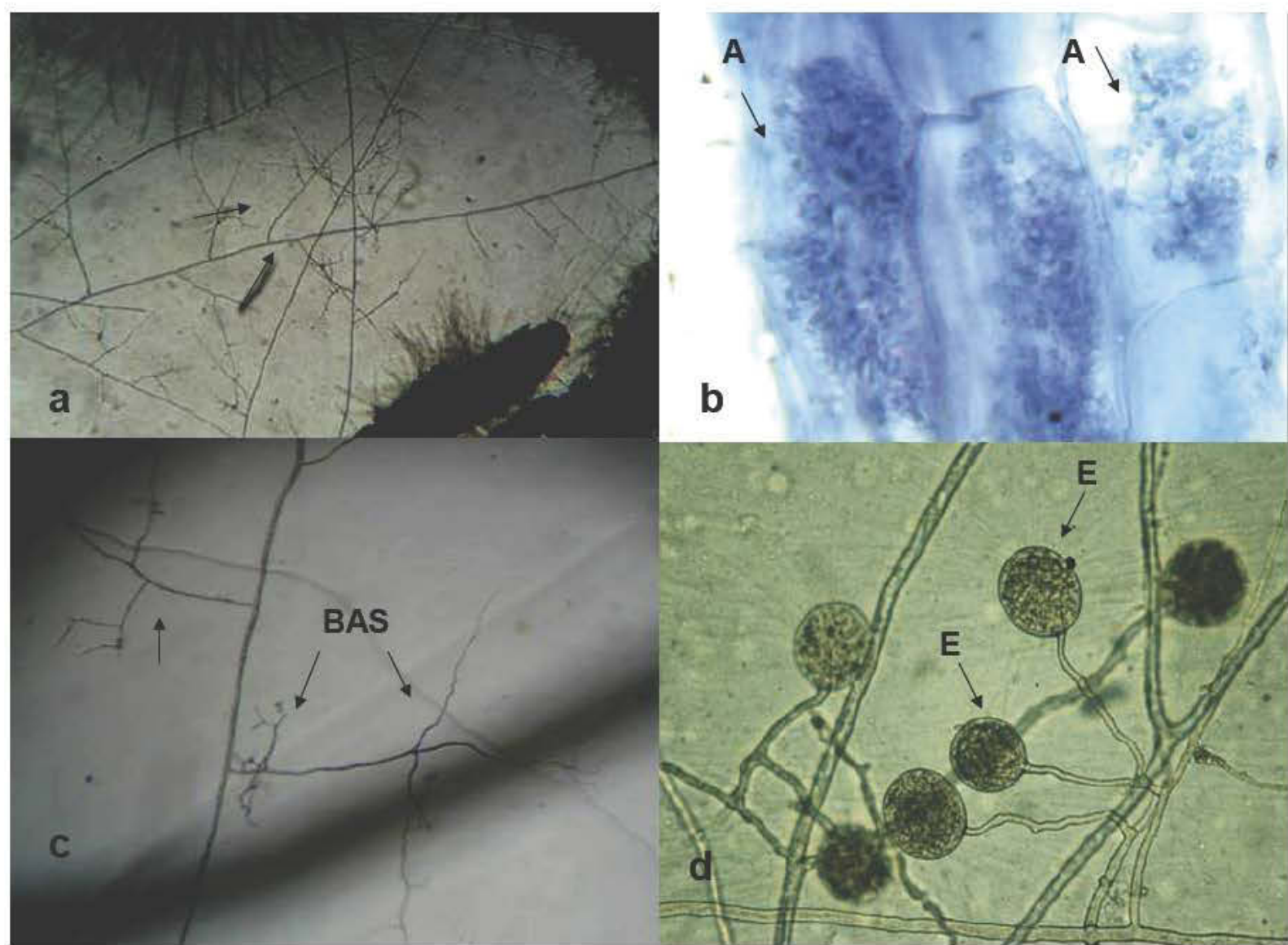

Figura 1. Desarrollo de estructuras típicas de la simbiosis entre Glomus sp (GEV02) y plántulas de mora bajo un sistema de cultivo autotrófico. a. Micelio extraradical b. formación de arbúsculos; c. Formación de BAS; d. formación de nuevas esporas. A: Arbúsculo, E: Espora.

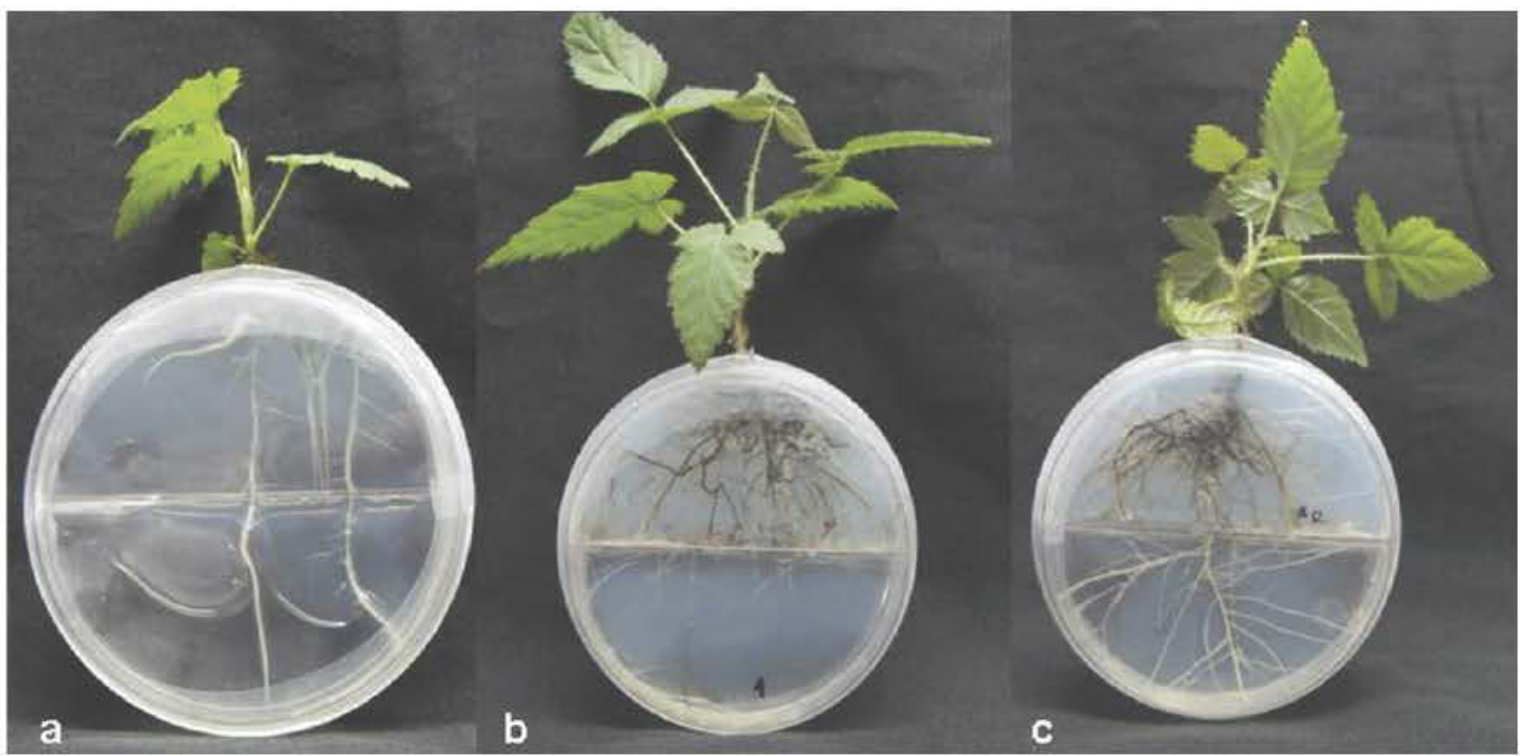

Figura 2. Imagen de plántulas de mora de castilla (Rubus glaucus, Benth) creciendo en un sistema de cultivo autotrófico con diferentes tratamientos durante nueve semanas. a. Control; b. Inoculado con esporas libres; c. Inoculado con fragmentos de raíces con vesículas. La imagen fue tomada al momento de la cosecha (novena semana). 
Tabla 1. Indicadores de asociación simbiótica entre el HF M A G lomus Sp. (GE V 02) - mora de castilla (Rubus glaucus, Benth) al momento de la cosecha, 9 semanas después de la inoculación (\% F : Frecuencia de micorrización; \% I: Intensidad de micorrización; \% a: Intensidad de arbúsculos).

\begin{tabular}{lccccc}
\hline Fuente de variación & \% F & \% & \% a & $\begin{array}{c}\text { L ongitud del micelio } \\
\text { extraradical }\end{array}$ & $\begin{array}{c}\text { Número de esporas } \\
\text { formadas }\end{array}$ \\
\hline Tratamientos & & & & - & - \\
\hline Control & - & - & - & $-171,56 a$ & $1078,0 a$ \\
\hline Esporas & $100 a$ & $7,8 a$ & $1,93 a$ & $1351,5 a$ \\
\hline Raíces con vesículas & $100 a$ & $7,4 a$ & $2,2 a$ & $538,33 a$ & 13,30 \\
\hline Coeficiente de variación & 0 & 21,32 & 12.1 & 15.36 & ns \\
\hline G M L & ns & ns & ns & ns & \\
\hline
\end{tabular}

ns: Diferencias no significativas $(P \leq 0,05)$, de acuerdo con el ANAVA

Letras diferentes indican: Diferencias significativas $(P \leq 0,05)$, de acuerdo con la prueba de Tukey.

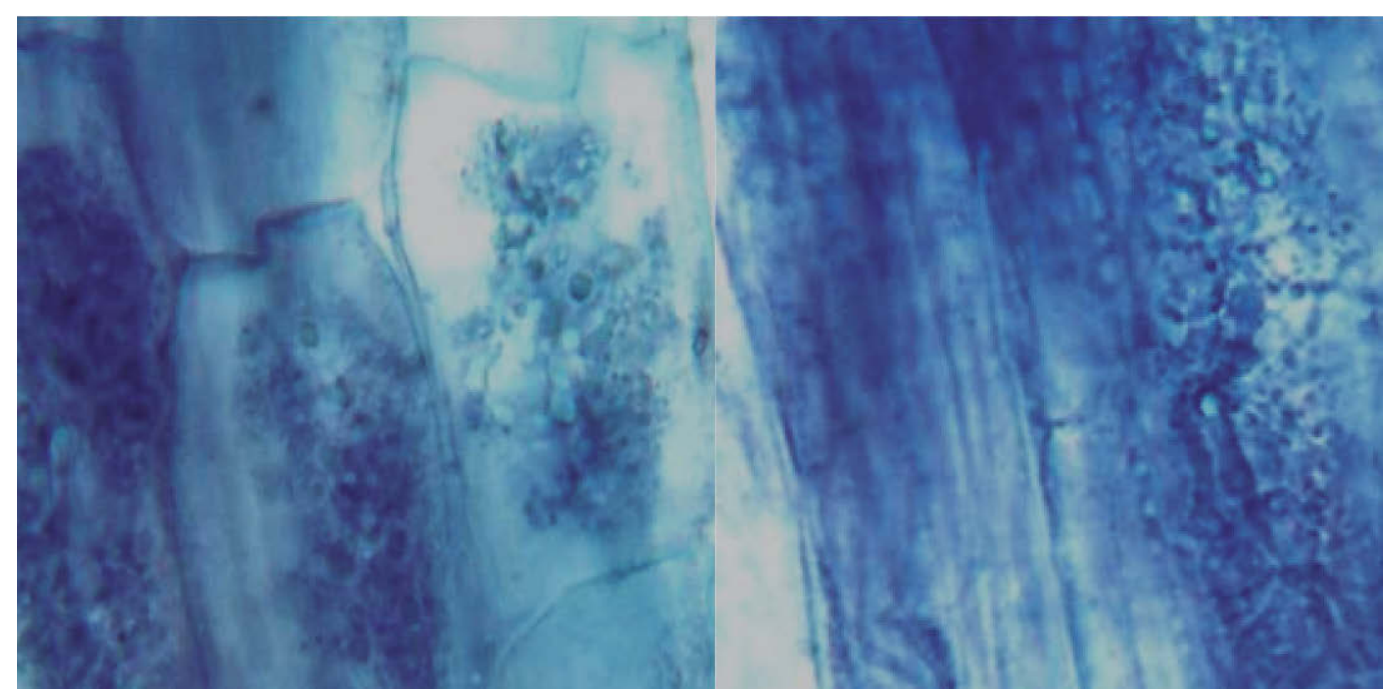

Figura 3. Formación de arbúsculos de Glomus sp (GEV 02) en raíces de mora bajo condiciones in vitro.

Peso seco radical $\square$ Peso seco áereo

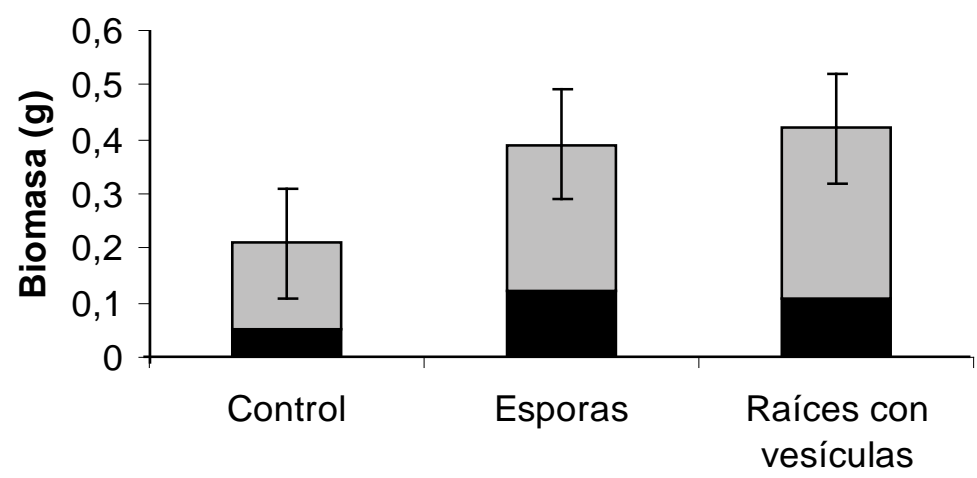

Tratamientos

Figura 4. B iomasa en plantas de mora de castilla (Rubus glaucus, B enth) inoculadas con Glomus sp. (GEV 02) al momento de la cosecha (novena semana). 

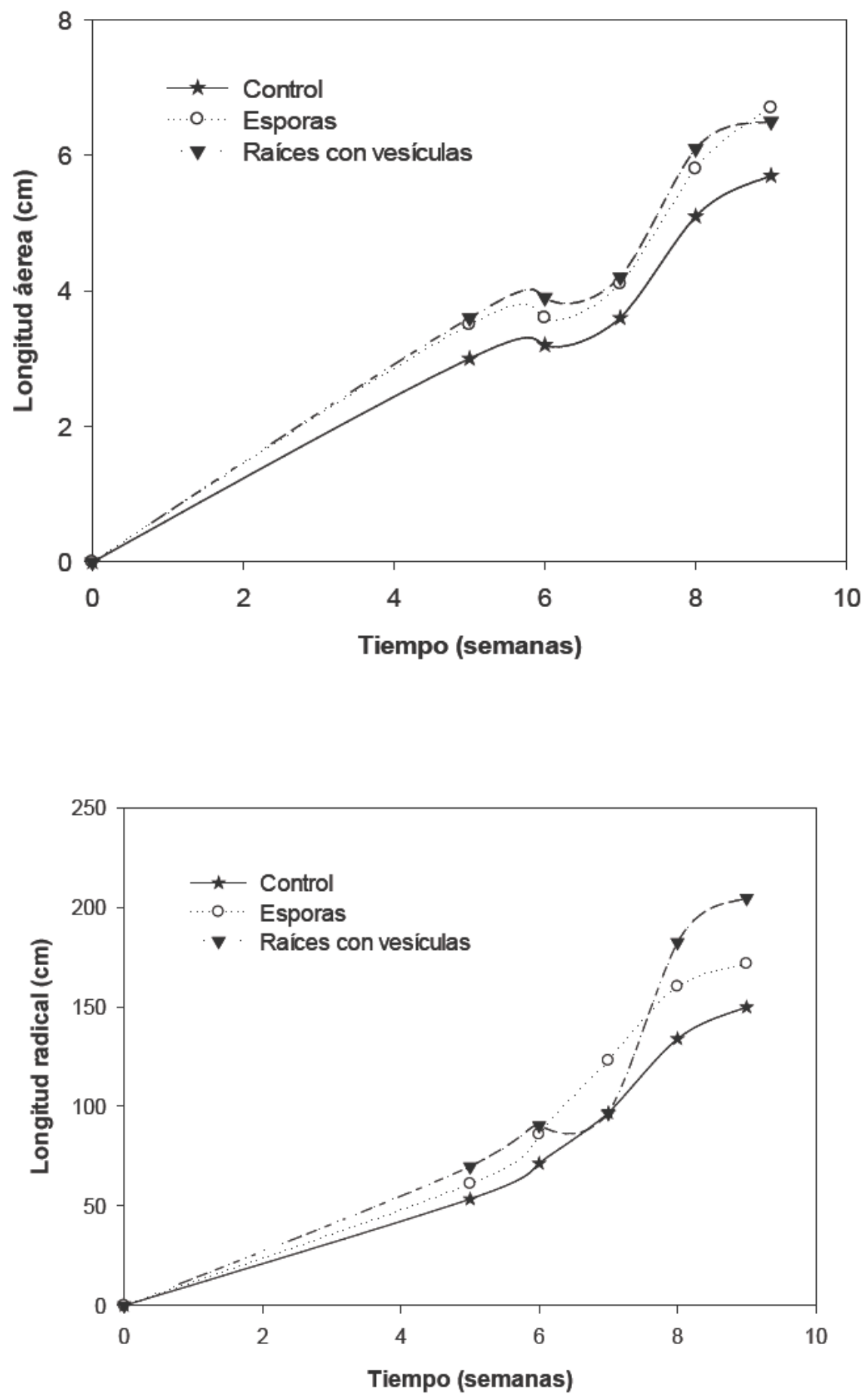

Figura 5. Crecimiento de la parte aérea y radical de las plantas de mora de castilla (Rubus glaucus, Benth) en sistema de cultivo autotrófico $(\mathrm{N}=5)$. 


\section{Discusión}

En este estudio se demostró que el sistema de cultivo autotrófico era adecuado para la micorrización in vitro de plántulas de mora. La longitud del micelio extraradical y la producción de esporas después de 6 semanas fueron similares a las obtenidas en plantas de papa (13). Nueve semanas después el HFMA Glomus sp. (GEV02) había producido una gran cantidad de micelio extraradical y de esporas. En presencia de las raíces de mora Glomus sp. (GEV02) desarrolló un abundante micelio extraradical con valores promedio de $471.56 \mathrm{~cm}$ para el tratamiento inoculado con esporas libres y $538.33 \mathrm{~cm}$ para el tratamiento inoculado con fragmentos de raíces con vesículas (Tabla 1). En el sistema de cultivo con plantas autótrofas se pudo detallar la arquitectura del micelio extraradical, donde se observaron las hifas principales y secundarias con una gran ramificación, así como la formación de BAS (del inglés Branched Absorbing Structures, Estructuras Ramificadas de Absorción); estas últimas estructuras se han propuesto como sitios preferentes para la producción de esporas (23). Los resultados observados en la arquitectura del micelio fueron similares a los observados en los primeros estudios que se realizaron bajo condiciones in vitro en cultivo monoxénico con raíces de zanahoria transformadas (23, 32). Según el análisis de varianza (GLM) no se observaron diferencias significativas $(P \leq 0,05)$ en el número de esporas entre los dos métodos de inoculación (esporas libres y fragmentos de raíces micorrizados) (Tabla 1), sin embargo, el tratamiento inoculado con fragmentos de raíces presentó un mayor número de esporas $(1351,5)$, en comparación con el tratamiento inoculado con esporas libres $(1078,0)$ durante las semanas evaluadas hasta la cosecha (Figura 6). Las esporas se formaron en hifas terminales en forma individual o en agrupaciones, fueron de un color blancoamarillo y contenían numerosas gotas de lípidos (Figura 7), su tamaño promedio varió de 60 a $90 \mu \mathrm{m}$

Estos estudios concuerdan con algunos realizados en cultivos monoxénicos donde utilizaron fragmentos de raíces de Allium porrum con vesículas o vesículas aisladas como inóculo $(17,25,33,34)$. Declerck et al., 1996a, demostraron que los fragmentos de raíces micorrizados presentaban un mayor potencial de inóculo que las esporas. Los fragmentos de raíz que contienen vesículas, producen múltiples hifas germinadas aumentando el número de puntos de penetración en la raíz. La esporulación en subcultivos es mayor con fragmentos de raíces micorrizadas que con esporas (17). Por el contrario, las esporas germinadas producen un número limitado de hifas infectivas y en consecuencia una tasa de colonización limitada (29).

A pesar que la composición mineral del medio MSR (Modificado Strullu - Romand) es más baja con respecto

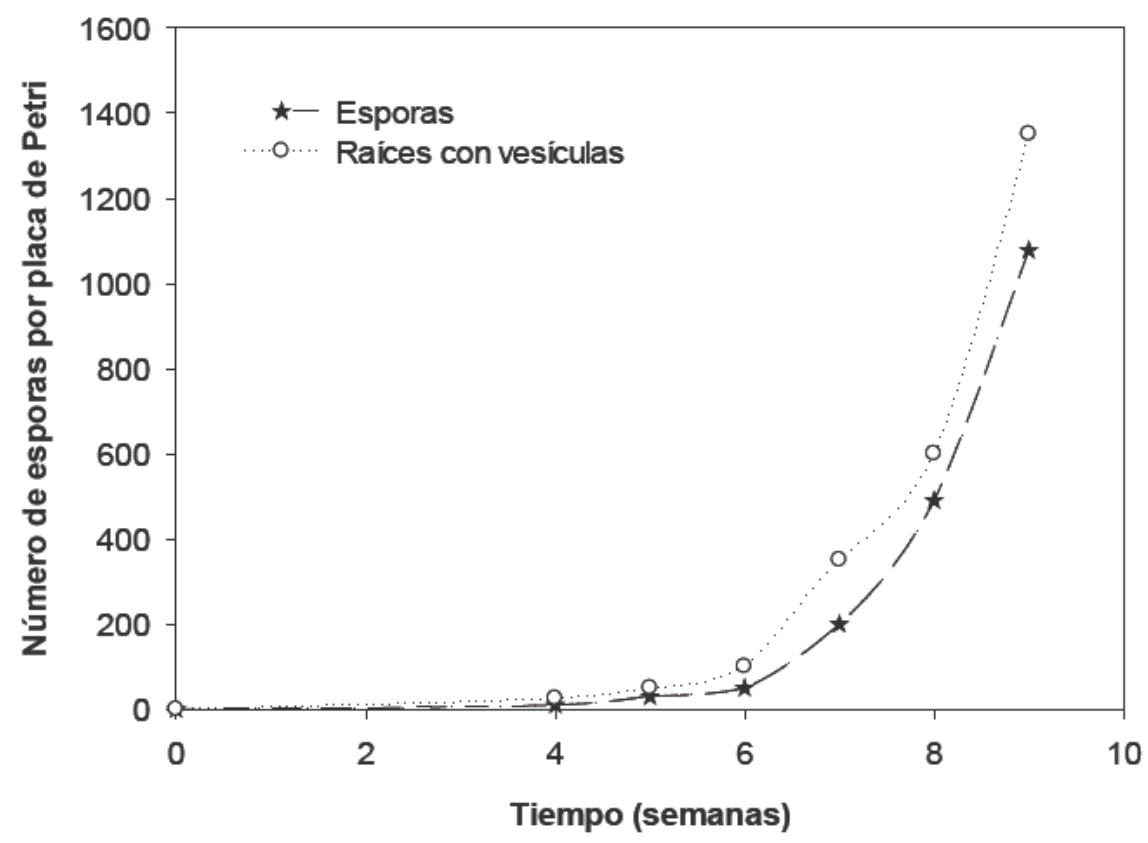

Figura 6. Dinámica de la producción de esporas de Glomus sp. (GEV02) asociadas a plantas autótrofas de mora de castilla (Rubus glaucus, Benth) en medio MSR libre de azúcar y vitaminas $(\mathrm{N}=5)$. 


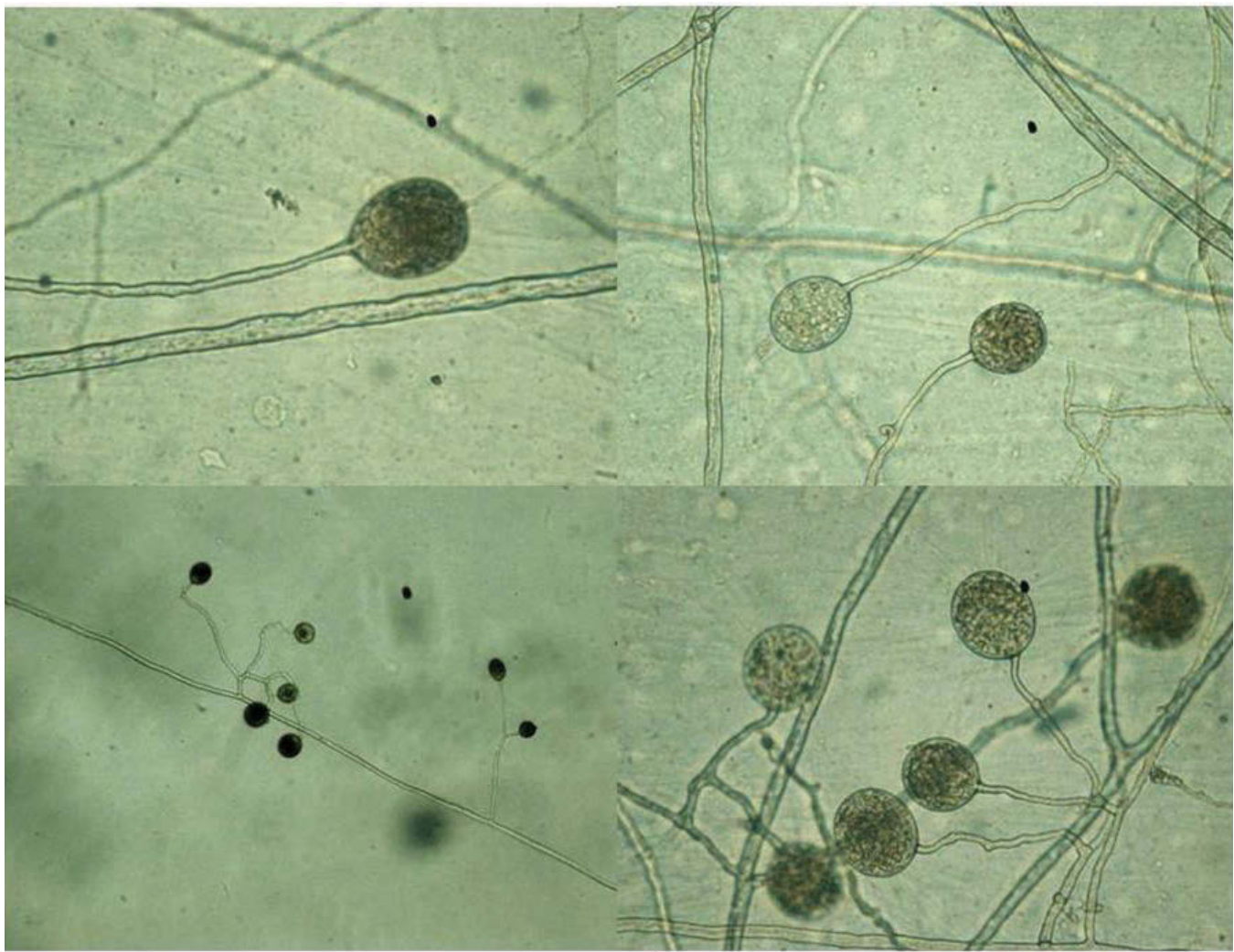

Figura 7. Formación de nuevas esporas de G lomus sp. (GEV 02) individualmente 0 en agrupaciones bajo condiciones in vitro. Imagen tomada en microscopio óptico (40X). a y b. esporas formadas individualmente; $\mathrm{c}$ y d. esporas formadas en agrupaciones

al medio Lepoivre utilizado en la micropropagación de plántulas de mora de castilla (Rubus glaucus, Benth) (17, 14), este medio libre de vitaminas y sacarosa permitió tanto el crecimiento de plántulas de mora, como la multiplicación de Glomus sp (GEV02), debido a que la actividad fotosintética de las plantas le proporcionaron carbono al HFM A para completar su ciclo de vida. Estos resultados demuestran el efecto positivo que puede tener el sistema de micropropagación autotrófica con respecto al sistema de micropropagación convencional. Se ha reportado (35) que la micropropagación con plantas autótrofas tiene muchas ventajas sobre la micropropagación convencional con respecto en la mejora de la fisiología de la planta en los cuales incluyen: aumento en el crecimiento y la tasa fotosintética; al tos porcentajes de supervivencia a condiciones ex vitro; eliminación de trastornos morfológicos y fisiológicos, sin la formación de callos en la base de los explantes (35). La micropropagación autótrofa se define estrictamente como la micropropagación sin sacarosa en el medio de cultivo, en los que el crecimiento o la acumulación de carbohidratos de los cultivos dependen por completo de la fotosíntesis y de la absorción de nutrientes inorgánicos (36-38).
El sistema de micorrización in vitro con plantas autótrofas pueden mejorar la condición física de las plantas in vitro y ex vitro, reflejado en un mayor crecimiento y desarrollo de estas, aumentando la capacidad fotosintética al expandir sus hojas, mientras que los HFM A mejoran el crecimiento y desarrollo de la planta al modificar la morfología de la raíz y el fortalecimiento en su función de absorción (39). Todos estos beneficios del sistema de cultivo autotrófico se vieron reflejados en este estudio, en donde los incrementos en biomasa de las plántulas de mora fueron mayores en los tratamientos inoculados con G lomus sp (GEV 02) con respecto al tratamiento no inoculado al cabo de las nueve semanas del experimento; resultados similares obtuvo N ogales (2009), en sistemas de cultivo autotrófico en plantas de vid inoculados con Glomus intraradices, en donde al cabo de la sexta - séptima semana las plantas produjeron una gran biomasa aérea y radical, y las raíces ocuparon casi la total idad de la caja de Petri no dejando casi espacio para seguir creciendo (27). A sí mismo, en sistemas descritos por diversos autores $(13,26,28)$, para cuando las plantas alcanzaron un nivel alto de colonización micorrícica, estaban prácticamente desarrolladas. En estudios realizados in vivo 
con mora de castilla (Rubus glaucus, Benth) y Glomus sp (M A 4) en la etapa de endurecimiento, se obtuvo una mayor acumulación de biomasa foliar y radical, área foliar y mejor estado nutricional $(\mathrm{P}, \mathrm{N}, \mathrm{Ca}$ y $\mathrm{M} \mathrm{g}$ ) de las plantas micropropagadas (40). Este estudio abre las puertas para investigar varios aspectos de la simbiosis, en donde plantas activas fotosintéticamente son necesarias.

\section{Conclusiones}

En el presenteestudio, las plántulas de mora micropropagadas se asociaron con éxito, por primera vez, con un Hongo Formador de Micorriza A rbuscular bajo condiciones in vitro. El sistema de cultivo autotrófico permitió el desarrollo del sistema simbiótico HFM A - G lomus sp. asociado a las raíces de plántulas de mora castilla micropropagadas en condiciones in vitro. $L$ os resul tados experimentales confirman la formación de estructuras típicas de la simbiosis, sin la necesidad de realizar muestreos destructivos. A demás de la alta producción de propágulos (como esporas), donde a partir de 5 esporas inoculadas se obtuvieron más de 1000 esporas en la novena semana después del establecimiento en sistema de cultivo autotrófico con plantas de mora, lo que indica que esta técnica puede ser una herramienta útil para la multiplicación de HFM A bajo condiciones in vitro, con fines de investigación.

\section{Financiación}

Esta investigación fue realizada con el apoyo del M inisterio de A gricultura y Desarrollo Rural y la Corporación Colombiana de Investigación A gropecuaria, en el marco del proyecto "Producción de ecotipos de mora (Rubus spp) evaluados y certificados para las principales zonas productoras de Colombia". Código M A DR: 2008 L 7642

\section{Conflicto de intereses}

Los autores expresan que no existen más que intereses científicos al rededor de los resultados de esta investigación.

\section{R eferencias}

1. A sohofrucol. Fondo $\mathrm{N}$ acional de fomento Hortofrutícola, Departamento Administrativo Nacional de Estadística, SISA C, M inisterio de A gricultura y desarrollo Rural. I Censo $\mathrm{N}$ acional de 10 frutas agroindustriales y promisorias. Bogotá, D.C., Colombia. 2004, 63p.

2. AGRONET. A nuario E stadístico, Secretario de la cadena dela mora. http//www.sioc.gov.co/A REA PRODUCCION/ A reaProduccion46.pdf. Consultado el 20 deE nero de 2012.
3. A ngulo R. Frutales exóticos de clima frío moderado. B ayer Crop Science S.A. Bogotá, D.C., Colombia. 2003; 99-118.

4. Cetz J. M icropropagación de chile dulce (Capsicum annuum L. var. Najera.) y chile habanero (C apsicum chinense Jacq.) con miras al mejoramiento genético del cultivo. Trabajo de Grado de Maestría. CA TIE, Turrialba, Costa Rica, 2005, 86 p.

5. V estberg M, Estaún V. M icropropagated plants, an opportunity to positively manage mycorrhizal activities. En: V estberg M, Estaún V. (eds). Impact of arbuscular mycorrhizas on sustainable agriculture and natural ecosystems. Birkhäuser, B asel. 1994; 217-226.

6. Elmeskaoui A, Damont J, Poulin M, Piché Y, Desjardins $Y$. A tripartite culture system for endomycorrhizal inoculation of micropropagated strawberry plantlets in vitro. Mycorrhiza 1995; 5, 313-319.

7. Alarcón A, Ferrera-Cerrato R. Ecología, fisiología y biotecnología de la micorriza arbuscular. IRENA T-Colegio de Postgraduados. M ontecillo. M undi Prensa, M éxico. 2000; 141-148.

8. K apoor R, Sharma D, B hatnagar A. A rbuscular mycorrhizae in micropropagation systems and their potential applications. Scientia H orticulturae 2008; 116, 227-239.

9. Declerck S, J ean-M ichel R, B runo D. Greenhouse response of micropropagated bananas inoculated with in vitro monoxenically produced arbuscular mycorrhizal fungi. Scientia H orticulturae 2002; 93, 301-309

10. Andrés A, Estrada-L una, Fred T, Davies J. A rbuscular mycorrhizal fungi influence water relations, gas exchange, abscisic acid and growth of micropropagated chile ancho pepper (Capsicum annuum) plantlets during acclimatization and postacclimatization. J ournal of Plant Physiology 2003; 160, 1073-1083.

11. Duponnois R, Plenchette $C$. Helper bacterium enhances ectomycorrhizal and endomycorrhizal symbiosis of A ustralian A cacia species. M ycorrhiza 2003; 13, 85-91.

12. JoséN, M entreddy SR, A nand $K Y$. M ycorrhizal fungi and growth and development of micropropagated Scutellaria integrifolia plants. Industrial Crops and Products 2007; 25, 169-177.

13. V oets $L$, D upré de B oulois H, Renard L, Strullu DésireGeorges, Declerck, S. Development of an autotrophic culture system for the in vitro mycorrhization of potato plantlets. FE M S M icrobiology Letters 2005; 248, 111-118.

14. V alderrama A na M ilena, Álvarez Roberto, B arrero L uz Stella, Robayo M ónica, Núñez Víctor. Validación y escalamiento de plántulas de mora in vitro y manejo ex vitro para entrega a agricultores de Silvana. En: Barrero 
L uz Stella. (eds). Caracterización, Evaluación y Producción de material limpio de mora con alto valor agregado. Corporación Colombiana de Investigación agropecuaria. Cundinamarca, Colombia. 2009; 84p.

15. Gendermann JW, Nicholson TH. Spores of mycorrhizal Endogone species extracted from soil by wet sieving and decanting. Transactions of the British Mycological Society. 1963; 46, 235-244.

16. Pérez Moncada UA, Ramírez Gómez M M, Moreno Conn L M, Franco Correa M. M etodología para la desinfección y germinación de esporas y fragmentos de raíces micorrizados con G lomus sp. (GEV 02) para su uso bajo condiciones in vitro. Revista Corpoica - Ciencia y Tecnología A gropecuaria 2011; 12 (2): 143-150.

17. Declerck S, Strullu DG, Plenchette $C$. In vitro massproduction of the arbuscular mycorrhizal fungus, G lomus versiforme, associated with Ri T-DNA transformed carrot roots. Mycological Research. 1996a ; 100 (10): 1237-1242.

18. Newman El. A method of stimating the total length of root in a sample. J ournal of A pplied Ecology 1963; 3, 139.

19. Phillips JM, H ayman DS. Improved procedure of clearing roots and staining parasitic and vesicular-arbuscular mycorrhizal fungi for rapid assessment of infection. Transaction of the British Mycological Society 1970; 55, 159-161.

20. Trouvel ot A, K ough J L, Gianinazzi-Pearson V. M esure du taux de mycorrhization V A d' un systéme radiculaire. Recherche de méthodes $d^{\prime}$ estimation ayant une signification fonctionnelle. In : Gianinazzi-Pearson V, Gianinazzi S. (eds). Physiological and Genetical A spects of M ycorrhizae. Paris, IN RA Press. 1986; 217-221

21. M ycocal.exe. (http://www.dijon.inra.fr/mychintec/ M ycocalc-prg/download.html). Consultado el 01 de Julio de 2011.

22. Bago B. Putative sites for nutrient uptake in arbuscular mycorrhizal fungi. Plan and Soil 2000; 226, 263-274.

23. Bago B, Azcón-A guilar C, Piché $Y$. A rchitecture and development dynamics of the external mycelium at the arbuscular mycorrhizal G lomus intraradices grown under monoxenic conditions. M ycologia 1998a; 90, 52-62.

24. B écard G, Fortin J. Early events of arbuscular mycorrhiza formation on Ri T-DNA transformed root. New P hytologist 1988; 108, 211-218.

25. Declerck S, Strullu D, Plenchette C. M onoxenic culture of the intraradical forms of $\mathrm{G}$ lomus sp. Isolated from a tropical ecosystem: a proposed methodology for germonplasm collection. M ycologia 1998; 90, 579-585.
26. Dupré de Boulois $H$, Voets $L$, Delvaux $B$, Jakobsen I, Declerck $S$. Transport of radiocaesium by arbuscular mycorrhizal fungi to Medicago truncatula under in vitro conditions. Environmental Microbiology 2006; 8, 1926-1934.

27. Nogales García A M. Estudio de la interacción entre el Hongo Formador de M icorrizas A rbusculares Glomus intraradices Schenck y Smith y el hongo patógeno Armillaria mellea (V ahl:fr) P. K uhn en Vid. Tesis Doctoral. Facultad de Biología. U niversitat de B arcelona, España, 2009, 222p.

28. K offi M Ch, Enrrique de la Providencial, Elsen A, Declerck S. Development of an in vitro culture system adapted to banana mycorrhization. African J ournal of Biotechnology 2009; 8 (12): 2750-2756.

29. V oets $L$, Enrrique de la Providencia I, Férnandez $K$, IJ do M, Cranenbrouck S, Declerck S. Extraradical mycelium network of arbuscular mycorrhizal fungi allows fast colonization of seedlings under in vitro conditions. M ycorrhiza 2009; 19, 347-356.

30. Gallaud I. Études sur les mycorrhizes endotrophes. Revue Générale de Botanique 1905 ; 17, 5-48, 66-83, 123-135, 223-239, 313-325, 425-433, 479-500.

31. Ludwig LM. Hormonal balance in plants during colonization of mycorrhizal fungi. In: Kapulnick $Y$ and Douds DD (eds). A rbuscular mycorrhizas: Physiology and Function. K luwer A cademic Press. 2000; 263-286.

32. Bago B, Cano C, A zcón-A guilar C, Samson J, Coughlan A P, PichéY. Differential morphogenesis of the extraradical mycelium of an arbuscular mycorrhizal fungus grown monoxenically on spatially heterogeneous culture media. M ycologia 2004; 96, 452-462.

33. Declerck S, Cranenbrouck S, DalpéY, Séguin S. G lomus proliferum sp. nov.: a description based on morphological, biochemical, molecular and monoxenic cultivation data. M ycologia 2000; 92 (6): 1178-1187.

34. Diop TA, Plenchette C, Strullu D G. Dual axenic culture of sheared-root inocula of vesicular-arbuscular mycorrhizal fungi associated with tomato roots. M ycorrhiza 1994a; 5,17-22.

35. Kozai T, Kubota C. Concepts, definitions, ventilation methods, advantages and disadvantages. In: K ozai T, A freen $F$, Zobayed SM A (eds). Photoautotrophic (sugarfree medium) micropropagation as a new propagation and transplant production system. Springer, Dordrecht. 2005; $19-30$

36. K ozai T. A cclimatization of micropropagated plants. In: $B$ ajaj Y PS (ed) B iotechnology in A griculture and Forestry. 
High-Tech and Micropropagation I. Springer-V erlag, B erlin, Germany. 1991; 127-141.

37. Zobayed SMA, A freen F, Xiao, Kozai T. Recent Advancement in Research on Photoautotrophic $M$ icropropagation U sing Large Culture V essels with Forced Ventilation. In Vitro C ellular and D evelopmental Biology- Plant. 2004; 40 (5): 450-458.

38. Xiao Y, Niu G, K ozai T. Development and application of photoautotrophic micropropagation plant system. Plant Cell Tissue and Organ Culture 2010; 105 (2) 149-158.
39. Liu Wen-Ke, Y ang Qi-Chang. Integration of mycorrhization and photoautotrophic micropropagation in vitro: feasibility analysis for mass production of mycorrhizal transplants and inoculants of arbuscular mycorrhizal fungi. Plant Cell Tissue and Organ Culture 2008; 95, 131-139.

40. Roveda $G, C$ abra $L$, Ramírez $M$, Peñaranda A. Efecto de las micorrizas A rbusculares sobre la aclimatación y endurecimiento de microplántulas de mora (Rubus glaucus). Revista Corpoica - Ciencia y Tecnología Agropecuaria 2007; 8(1): 28-36. 